\title{
What Students' Arguments Can Tell Us: Using Argumentation Schemes in Science Education
}

\section{Fabrizio Macagno \& Aikaterini Konstantinidou}

\section{Argumentation}

An International Journal on Reasoning

ISSN 0920-427X

Volume 27

Number 3

Argumentation (2013) 27:225-243

DOI 10.1007/s10503-012-9284-5

\section{ARGUMENTATION}

Volume 27 No. 32013 
Your article is protected by copyright and all rights are held exclusively by Springer Science +Business Media Dordrecht. This e-offprint is for personal use only and shall not be selfarchived in electronic repositories. If you wish to self-archive your article, please use the accepted manuscript version for posting on your own website. You may further deposit the accepted manuscript version in any repository, provided it is only made publicly available 12 months after official publication or later and provided acknowledgement is given to the original source of publication and a link is inserted to the published article on Springer's website. The link must be accompanied by the following text: "The final publication is available at link.springer.com". 


\title{
What Students' Arguments Can Tell Us: Using Argumentation Schemes in Science Education
}

\author{
Fabrizio Macagno $\cdot$ Aikaterini Konstantinidou
}

Published online: 9 November 2012

(C) Springer Science+Business Media Dordrecht 2012

\begin{abstract}
The relationship between teaching and argumentation is becoming a crucial issue in the field of education and, in particular, science education. Teaching has been analyzed as a dialogue aimed at persuading the interlocutors, introducing a conceptual change that needs to be grounded on the audience's background knowledge. This paper addresses this issue from a perspective of argumentation studies. Our claim is that argumentation schemes, namely abstract patterns of argument, can be an instrument for reconstructing the tacit premises in students' argumentative reasoning and retrieving the background beliefs that are the basis of their arguments. On this perspective, the process of premise reconstruction is followed by a heuristic reasoning process aimed at discovering the students' previous intuitions that can explain the premises and concepts that are left unexpressed in their arguments. The theoretical insights advanced in this paper are illustrated through selected examples taken from activities concerning predictive claims on scientific issues.
\end{abstract}

Keywords Argumentation - Education - Argumentation schemes · Persuasion · Reasoning · Conceptual change · Prior beliefs · Argument from cause · Analogy

\footnotetext{
F. Macagno $(\bowtie)$

ArgLab, Instituto de Filosofia da Linguagem (IFL), FCSH, Universidade Nova de Lisboa, Edifício I\&D, 4 andar, Avenida de Berna 26, 1069-061 Lisbon, Portugal e-mail: fabriziomacagno@hotmail.com; fabrizio.macagno@fcsh.unl.pt
}

\section{A. Konstantinidou}

Faculty of Teacher Training, Universitat de Barcelona, Passeig de la Vall d'Hebron, 171, 08035

Barcelona, Spain

e-mail: konstantinidou@ub.edu 


\section{Introduction}

The role of argumentation in science education has been stressed by a growing literature that emphasized the problem of constructing students' knowledge taking into account their previous beliefs (Sampson and Clark 2008; Schwarz and De Groot 2007; Driver et al. 2000; Duschl et al. 1999; Jimenez-Aleizandre et al. 2000; Kelly and Takao 2002; Erduran and Jimenez-Aleixandre 2007; Castells et al. 2007). On this view, teaching can be regarded as a dialogue aimed at persuading the interlocutors, providing them with reasons for accepting new or different scientific views. In order for this conceptual change to happen, the students' prior beliefs cannot be simply replaced by new ideas. On the contrary, such prior understanding becomes the ground and the target of the teacher's arguments, aimed at leading the students to regard the (new) scientific ideas as more predictive and convincing than the ones based on their own experience (Carey 2000; Hewson 1992).

This relationship between beliefs, arguments and teaching constitutes the framework of this paper. Since education can be thought of as an argumentative dialogue, the argumentative skills and the analysis of argumentation structures becomes crucial (Erduran et al. 2005). In particular, in science education the best known and common tools provided by argumentation theory are the analytical ones developed by Toulmin, which have been used for improving the students' arguments and their interactive procedures (Duschl 2007: 165). These researches showed how students' arguments supporting predictive claims about scientific problems can reveal much more than reasoning skills. By making the different components of their arguments explicit, the students can bring to light important grounds of their scientific ideas, which can be later addressed, investigated and questioned. On this perspective, the analysis of the structure of the students' reasoning can become an instrument for revealing their background beliefs, which are fundamental for the process of learning. However, how can such beliefs be identified and reconstructed starting from the evidence represented by the students' arguments?

The purpose of this paper is to introduce and illustrate how a tool developed in argumentation theory, argumentation schemes, can be used in the field of science education for uncovering the structure of the students' background beliefs underlying their arguments. Argumentation schemes (Walton 1995; Walton et al. 2008, or argument schemes, see Van Eemeren and Grootendorst 2004) are abstract pattern of reasoning outlining the semantic and logical structure of the premises and the conclusion of the most common types of argument. For this reason, they can be used for retrieving tacit premises and unstated concepts and assumptions of an argument. In particular, our theoretical goal is to show how the reconstruction of such implicit components can reveal students' prior beliefs on which their scientific reasoning, in particular their predictive claims about scientific problems, is based (Konstantinidou et al. 2010).

This proposal addresses from a theoretical perspective the relationship between a quasi-logical and dialectical tool and the epistemic notions of belief and conceptual change. For this reason, we will first investigate how beliefs are connected with conceptual change, showing their importance for persuasion and teaching. As a second 
step, the crucial question of the relationship between beliefs and tacit premises will be addressed, and in particular the role of the latter as valuable signs of fundamental prior concepts (van Rees 2001: 189). The third point that needs to be tackled is the problem of interpretation: the same argument can be interpreted in different fashions, resulting in different reconstructions of its implicit premises (van Eemeren et al. 1994). By specifying the specific material relations between premises and conclusion, argumentation schemes outline the structure of the elements left implicit and, for this reason, can provide the most reasonable reconstruction of the hidden premises. Finally, in order to show how this instrument can be applied to real cases, we will illustrate our theoretical proposal through the analysis of some students' arguments, outlining the process of premise reconstruction, the retrieval of possible background beliefs, and the critical questioning of the tacit dimension of an argument.

\section{Beliefs and Teaching}

One of the crucial issues in education is the retrieval of previous beliefs (Roschelle 1995). Students, during the course of their lives, have developed their "private understanding" (Mestre 1994) of scientific concepts and phenomena, such as speed, force or heat. Such understanding often amounts to concepts having meanings different from the scientific ones and to beliefs that are often incomplete, fragmented and "fraught with preconceptions" (Mestre 1994). These preconceptions can be, and often are, in conflict with scientific concepts and need to be addressed in order for the students to change their beliefs for two reasons. First, prior beliefs can affect the understanding and interpretation of scientific texts (Guzzetti et al. 1993). Just like the story of Fish is fish, in which the fish interprets all the descriptions on the life on land in a fish-like form, everything the student hears risks being incorporated into his preexisting view (Bransford et al. 2000: 10-11). Second, background beliefs, even if fragmented and incomplete, are based on reasons that make them hard to change or be modified by scientific texts or arguments (Southerland et al. 2001). These justifications, not accepted in the scientific community, or simply weak or insufficient, need to be analyzed and rebutted by stronger scientific warrants in order for the learner to be persuaded and a conceptual change to occur (Duit 1999).

As the aforementioned studies underscore, the students' background conceptions need to be taken into consideration in education (Sutton 1996: 146; see also Martins et al. 2001). According to Hewson (1992), if a new conception conflicts with a prior belief, it cannot be accepted until the student is somehow dissatisfied with it and the background conception is rebutted by a more explicative one. For these reasons, learning can be conceived as a process of developing and addressing prior beliefs (Osborne et al. 2004: 995, Carey 2000: 13-14). A scientific idea, for instance, needs not only to be understood, but also to be accepted as the best explanation of a phenomenon and the most predictive model (Songer and Linn 1991: 763). Background beliefs and the reasons on which they are based need to be retrieved and taken into account, so that they can be undermined and confronted with more intelligible, more plausible or more predictive scientific conceptions (Hewson 1992: 11; Posner et al. 1982). 
The process of teaching, or rather the process of modifying the interlocutors' background beliefs, should be regarded as essentially argumentative (see Pera and Shea 1991; Koballa 1992; Sandoval and Millwood 2005; Osborne et al. 2004), as grounded on the interlocutors' background experience (Baker 2003: 48) and previous beliefs and interests. Teaching can be ideally considered as an argumentative persuasive dialogue for two reasons. First, it is aimed at modifying and developing the other's "private understanding", showing its limits or building on it in order to account for new phenomena (Simons et al. 2001: 7; Chi and Roscoe 2002). Second, one of the crucial instruments used for achieving such a purpose is the use of arguments, which intervene at two levels. On the one hand, students' argument can be encouraged in order to bring to light the background beliefs on which they are based; on the other hand, they can be used for providing reasons showing their incompleteness and supporting the scientific viewpoint.

For these reasons, the teaching activity fundamentally falls within the framework of argumentation studies, and in particular within the models that analyze dialogue aimed at the persuasion of the interlocutor (van Eemeren and Grootendorst 1984, 1992, 2004; Walton 1984; Walton and Krabbe 1995). As pointed out in the ancient theories, persuasion is characterized by the freedom of choice, and is the result of a process of modification of one's beliefs (Rigotti 1995: 11), or rather propositions he is committed to (Walton and Krabbe 1995). When our interlocutors find an argument persuasive, it is generally because they think it is reasonable and it proceeds from premises that they accept or they are committed to (Walton 2007: 86). For this reason, the effectiveness and persuasiveness of teachers' arguments depend on what the students' hold as acceptable or reasonable. As a consequence, the process of reconstruction of the possible previous beliefs of the students becomes crucial. Such a reconstruction can be carried out only through a dialectical activity (Nussbaum 2011), a persuasion dialogue in which the speaker retrieves the basic assumptions of the interlocutor's arguments.

However, how can the teacher (or more generally the speaker) reconstruct the background beliefs on which the interlocutor grounds his arguments? What is the relationship between arguments, and in particular the tacit premises thereof, and beliefs?

\section{Retrieving Background Beliefs}

The contribution of argumentation theory to the analysis and reconstructing of prior beliefs in teaching hinges on the crucial relationship between the dialectical notion of commitment and the epistemic one of belief. How can a tacit premise lead to an epistemic status?

\subsection{Commitments and Beliefs}

In argumentation theory, the dialectical and reasoning structure of dialogues is grounded on the notion of commitment. Arguments are conceived as patterns of reasoning transferring the acceptability of the premises, or rather the strength of the 
interlocutor's commitments to some propositions, to the conclusion (Hahn and Oaksford 2006). This model of dialogue is based on two parties, called the proponent (or speaker) and the opponent (or hearer), and each tries to persuade the other to accept a claim by using arguments to prove it. The interlocutors intend to change the other party's commitments, which can be the description of a state of affairs (Bob stole the milk) or a judgment (Bob is a thief). The instrument to lead the interlocutor to change their position is a chain of arguments based on premises belonging to the implicit ground that he shares. This model of argumentative dialogue is not based on beliefs, which cannot be known or retrieved, but rather on commitments, what the interlocutor can be accountable for based on what he says and takes for granted.

The dialogical notion of commitment used in argumentation theory is distinct from the psychological concept of beliefs, which is of crucial importance in education. However, the two concepts are related. Commitments can be regarded as signs of the speaker's beliefs (Godden 2010). On this view, one of the possible explanations of a commitment is belief (one commits himself because he believes it). In specific dialogical teaching activities, this explanation can be considered the best one. For instance when the students are requested to advance predictive claims and justify them based on their opinions, explicit or implicit commitments are usually regarded as revealing background conceptions. In such cases other possible explanations, such as the student's desire to win the argument, are of secondary relevance compared to presuming his belief in the proposition he committed to.

Another crucial issue in the relation commitment-belief is the multiplicity of beliefs that can explain a commitment. For instance, we can consider the following predictive claim:

The melting of ice floating in water results in an increase of the water level.

This commitment can be explained by different beliefs. The student may not know the buoyancy force; or he may not have considered the submerged part of the ice; or he may not know that a part of ice is submerged, etc. However, the level of education of the student may exclude some options and privilege a specific explanation. Moreover, the purpose of the dialogue between teacher and student can lead to opting for a belief-explanation more focused on potentially lacking or incomplete concepts. We can represent the explanatory relationship between commitments and beliefs in Fig. 1.

The crucial role of background information is emphasized in the models of argumentative dialogue. The change of attitude that this type of dialogue aims at is based on the knowledge that the interlocutors share. They can persuade each other because they proceed from a set of commonly accepted propositions. The problem that the models of argumentative dialogues face is to develop a procedure for revealing the interlocutors' hidden commitments. Krabbe introduced the idea of metadialogue as a dialogue on the conditions of the discussion (Krabbe 2007: 240-241). In this phase the interlocutors solve problems of deep, non-explicit commitments (Krabbe 2003: 641; Finocchiaro 2007). In Walton's persuasion dialogue, the persuasion process is based not only on the explicit commitments of the parties, but also on the so-called implicit (or dark-side) commitments (Walton 


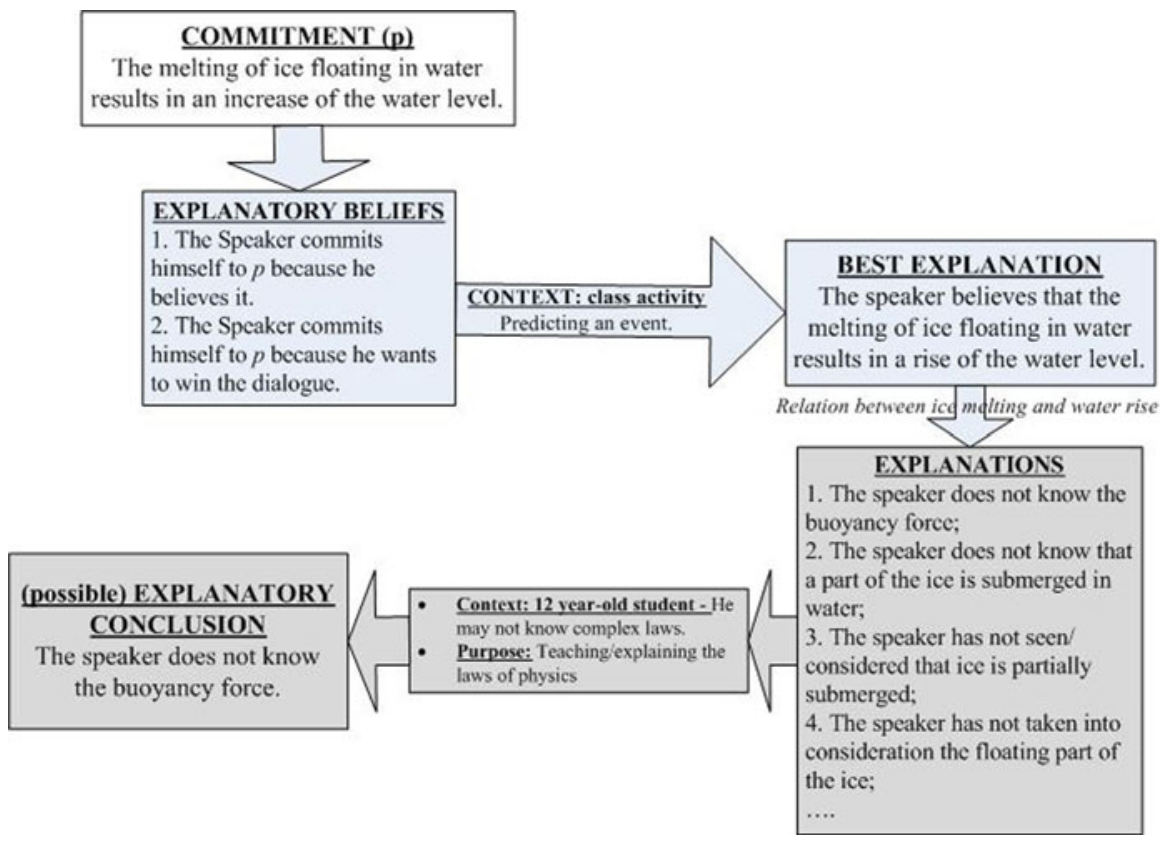

Fig. 1 Beliefs as possible explanations

and Krabbe 1995). These commitments are not revealed, but are used during a dialogue in order to build up persuasive arguments. For instance, in the aforementioned argument the speaker is not committed only to the explicit premises, but also to the conditional, hidden one that supports the conclusion, namely "If Bob stole public money then he is a thief". Such a proposition is treated as part of the interlocutors' common ground and is the foundation of the argument persuasiveness.

\subsection{Reconstructing Tacit Premises}

The process of reconstruction of implicit commitments plays a fundamental role in argumentation. On the one hand, the hearer can come to know the implicit foundations of the other's position by reconstructing his or her arguments and the grounds thereof. On the other hand, the speaker can explain the success or failure of a piece of reasoning by analyzing the propositions taken for granted and not accepted by the other party (Walton 1984: 252-254). In these cases, implicit commitments can be brought to the light side, discussed and negotiated or corrected. By revealing, defending and retracting implicit commitments, the parties discover the real deep disagreements underlying their difference of opinion. On this perspective, the investigation of the implicit commitments is a dialogical process that results in a redefinition of the problem at issue to make it more understandable or acceptable to the other party (see also Baker 2003). 
The instruments of argumentation theory can be applied to the dialogical process of teaching. As mentioned above, teaching as a whole can be considered a persuasive process that somehow needs to address students' background beliefs. The argumentative dimension of teaching emerges when the students need to justify predictive claims, or when the teacher needs to support a specific viewpoint (such as specific conceptions in an explanation) or counter the positions of his interlocutors. Moreover, as the modern approaches pointed out, the teaching activity needs to take into account the prior beliefs of the students. For this reason, the process of reconstructing the implicit premises becomes crucial for identifying the possible "private understanding" of a concept or a phenomenon.

Given this relationship between teaching and prior beliefs, and between beliefs and commitments, the tools of argumentation theory used for the analysis and assessment of arguments can be useful resources for education research. In particular, one of the most crucial instruments of premise reconstruction in argumentation, argumentation schemes, can be an important tool also for teachers. The argumentative reasoning patterns can reveal the most reasonable missing premises and concepts underlying students' arguments and predictions, and can be used as both an analytical and dialogical tool to teaching. Even though such "implicit commitments" do not represent the students' beliefs, they can be considered as the argumentative positions for which they can be held to be accountable, namely what can be addressed in a dialogue and be the target or subject matter of further discussions.

\section{An Instrument for Retrieving Implicit Premises}

Students advance predictive claims or justify their viewpoints by advancing arguments that are borne out by explicit or implicit premises, or that can be more or less complete (Osborne 2005: 371-372). Their arguments can hide implicit information of two kinds. One of the premises needed for the conclusion to follow can be missing, or rather be hidden (van Eemeren et al. 2002; Hitchcock 2003; Groarke and Tindale 2004). Arguments are often enthymematic in nature, as they leave some of the premises on which they are based unexpressed (Braet 1999; Levi 1995). The reconstruction of this implicit link between premises and conclusion allows one to understand the reason or the principle supporting a specific view. However, the "logical" implicit premise allows the conclusion to follow, but often does not represent the semantic relation between the concepts which can bring to surface the background beliefs of the students concerning a specific issue. For instance, in the argument "The ice melts. Therefore the level of the water in which it is floating increases" the premise "If the ice melts, the water level increases" can be the reconstructed implicit "logical" premise. However, this does not reveal anything about the material, semantic relation underlying the argument, such as cause-effect, correlation, definition, etc. In the following sections we will show how the use of abstract and prototypical patterns of reasoning called argumentation schemes (Walton and Macagno 2006), can be used as instruments for revealing this twofold type of hidden information. 


\subsection{Reconstructing Arguments}

Argumentation theory has provided a framework for the structural analysis of arguments, still prominent today. Toulmin's (1958) framework, broadly introduced in research in the field of science education (e.g., Bell and Linn 2000; Erduran et al. 2004; Jimenez-Aleizandre et al. 2000; Kelly and Chen 1999), has provided researchers with a theoretical perspective on argument that involves conceptualizing argument in terms of linked components. The advantage to researchers of adopting this framework is that it can be used to assess the quality of argumentation in terms of identifying the number of components, hence the complexity of the arguments used (Simon 2008).

Following Toulmin (1958) an argument can be represented as an interconnected set of (1) a claim (C), (2) data (D), (3) warrants connecting claim and data ("since W"), (4) backings (B) substantiating the warrants, and (5) rebuttals (R), which indicate under which circumstances the stated claim would be correct. Qualifiers (Q) describe the strength of the inferences and how universally they can be applied and are valid. The structure of Toulmin's model is represented in Fig. 2.

For instance, the student can argue that the melting of ice will result in an increase of the water level (Claim) based on the fact that the melting of the polar ices results in a rise of the sea level (Datum). In this case the warrant and the backing are missing. Most of the current models based on this structure are aimed at improving students' arguments, by teaching them to make all the structural elements explicit. For instance, in this case the students should have provided all the elements supporting their claim and expressed the premise they left implicit.

Building on the research advanced in Duschl et al. (1999), Simon (2008), we maintain that the argument approach to teaching can be also used for the purpose of argument analysis and premise reconstruction. In other words, the argument structure does not apply only as a normative tool, but as an interpretative instrument. Our research will be focused on how argumentation schemes can help us find an analytical framework to explore students' ideas in science and discover their implicit premises and beliefs. Such a process of reconstruction can become a starting point for further dialogical and argumentative activities, aimed at undermining previous incomplete conceptions and leading the student to assessing and changing his prior beliefs.

\subsection{Argumentation Schemes}

Well-constructed and complete arguments can provide understanding of students' underlying beliefs about science. However, just like every everyday argument, the

Fig. 2 Toulmin's structure of argument analysis

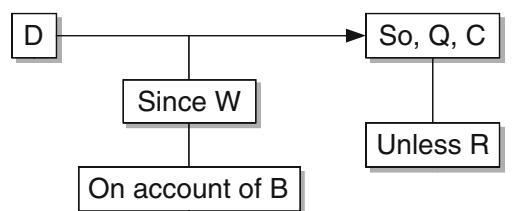


reasons supporting the conclusions (or rather the specific opinions) are often hidden. In order to uncover such principles it is necessary to delve into the analysis of argument, considering the components and the reasoning structure underlying them.

The passage from argument analysis to reasoning and therefore warrant analysis can be found in Toulmin's The Uses of Argument, where he defines warrants as "general, hypothetical statements, which can act as bridges, and authorize the sort of step to which our particular argument commits us" (Toulmin 1958: 91). These warrants can be different in nature, and therefore can be grounded on laws, principles of classification, statistics (Toulmin 1958: 98; 116), authority (Toulmin 1958: 198), causal relations or ethical principles (Toulmin 1958: 162). This generic idea was further developed by classifying arguments according to their possible types of warrant (Toulmin et al. 1984: 199) (Fig. 3).

Toulmin's concept of warrant is crucial for describing the types of argument. However, it does not provide an instrument for reconstructing them. Building on Toulmin's idea of warrant, Hastings developed the idea of modes of reasoning, that is, prototypical patterns of argument organized according to the type of warrant. An argument pattern (or scheme) was analyzed as a set of abstract premises leading to a conclusion based on a generic statement that authorizes a step in an argument (Hastings 1963). Every argument can be classified according to some categories of warrant (example, classification, definition, sign, cause, circumstance, comparison, analogy, testimony) and fit into one of the patterns, so that the hidden premise can be reconstructed by specifying the abstract variables of the scheme.

Walton developed Hastings' proposal, inquiring into the relationship between the principles of reasoning and the semantic relation between premises. The patterns of arguments were labeled as argumentation schemes, abstract structures merging together an inferential relation, or rule, systems of reasoning and logical rules (Walton and Macagno 2006; Macagno and Walton 2010). Every argumentation scheme has a set of critical questions, which point out the potential weak points of the reasoning. Critical questions are dialectical tools for testing the strength of the argument or the premises it is based on. Moreover, they can be considered as

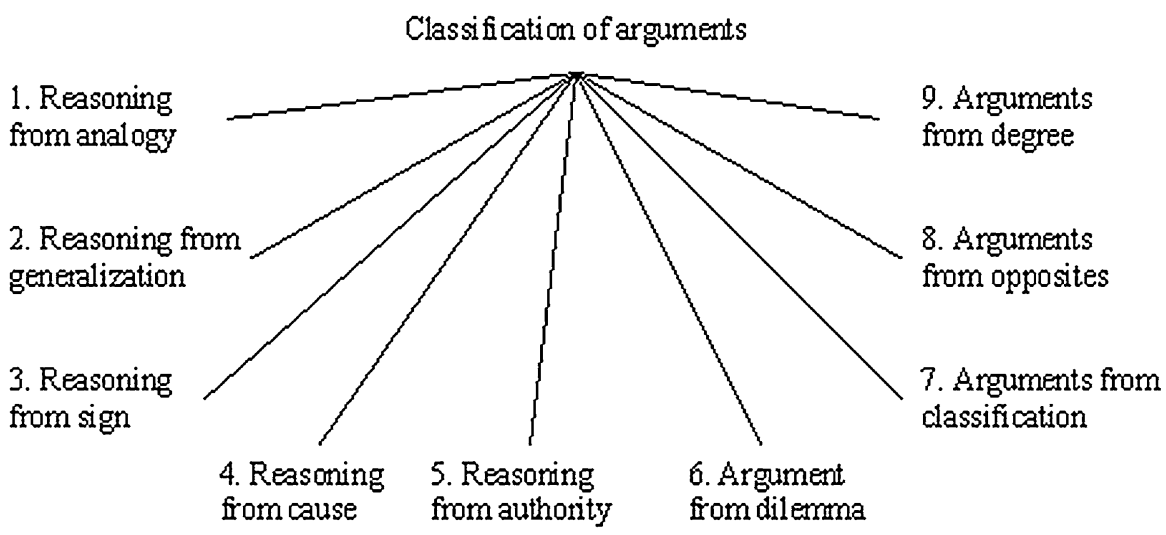

Fig. 3 Toulmin's classification of argument schemes 
guidelines for leading the interlocutor to make the deeper grounds of his or her arguments explicit. For instance we can consider the argument from cause to effect and argument from analogy, which are often used in the context of science education. The first argument represents the causal relationship between two events.

\title{
4.2.1 Argumentation Scheme 1: Argument from Cause to Effect (from Walton 1995: 140-141)
}

\author{
CAUSAL LINK Generally, if A occurs, then B will occur. \\ FACTUAL PREMISE In this case, A occurs. \\ CONCLUSION Therefore in this case, B will (plausibly) occur.
}

In this scheme we notice that the correlation between the two events A and B is expressed as a causal relation. For instance, if we consider the argument "The water level will rise when ice immerged in it melts, as liquid takes more space", we can identify the causal relationship and reconstruct the structure of the missing premise (If liquids take up more space than solids, melted ice will cause the water level to raise). In this case, the causal relationship is suggested by the ground provided (melting causes an increase in volume). The reconstruction of an argument structure often reveals deeper background knowledge. In order to show the causal relationship and the way it is related with the premise, it is necessary to reconstruct further causal links.

Argumentation schemes can be used not only as instrument for interpreting the interlocutor's reasoning, but also as a tool for attacking it or leading the hearer to provide further arguments (Nussbaum 2011). Every argument has a set of critical questions that are focused on the crucial aspects of the scheme. For instance we can consider the following questions associated with the argument from cause:

\section{Critical questions}

$\mathrm{CQ}_{1}$ : How strong is the causal generalization?

$\mathrm{CQ}_{2}$ : Is the evidence cited (if there is any) strong enough to warrant the causal generalization?

$\mathrm{CQ}_{3}$ : Are there other causal factors that could interfere with the production of the effect in the given case?

In the example mentioned above, all of the aforementioned questions can be used to lead the interlocutor to make the tacit reasons supporting his reasoning explicit. The hearer can provide a tentative interpretation of the argument, for instance advancing a causal reconstruction of the argument and investigating the possible underlying assumptions. For instance, the student can be asked to confirm, support or justify the causal relation between the melting of ice and an increase of water volume (first question). He or she may confirm or reject the interpretation, and advance other causal laws or examples drawn from his or her experience. With the second question the speaker can investigate whether the interlocutor knows cases in which the generalization fails. The third question can be used to lead the interlocutor to take into consideration other factors, such as the buoyancy force, which trigger different effects. The argumentation scheme, together with its critical questions, works not as 
a unilateral instrument of text analysis, but as a dialogical tool for discovering and expressing the tacit premises and concepts within the student's argument.

The argument from analogy is more problematic:

4.2.2 Argumentation Scheme 2: Argument from Analogy (Walton et al. 2008: 315)

GENERALIZATION Generally, case $C 1$ is similar to case $C 2$.

SIMILARITY Proposition $A$ is true (false) in case $C 1$.

CONCLUSION Proposition $A$ is true (false) in case $C 2$.

\section{Critical questions}

$\mathrm{CQ}_{1}$ : Are there differences between $C 1$ and $C 2$ that would tend to undermine the force of the similarity cited?

$\mathrm{CQ}_{2}$ : Is $A$ true (false) in $C 1$ ?

$\mathrm{CQ}_{3}$ : Is there some other case $C 3$ that is also similar to $C 1$, but in which $A$ is false (true)?

The argumentation scheme from analogy can be helpful for reconstructing the nature of the generalization underlying an analogy. For instance, we can consider the claim that the melting of ice cubes immerged in water will result in an increase of the water level, because the melting of ice caps causes the rise of the sea level. In this case, the premise reconstructed would be that ice caps are similar to ice cubes. However, the nature of this similarity and the factors considered in establishing it cannot be retrieved. Critical questions can be a useful instrument for eliciting implicit knowledge, but they presuppose further dialogical activities.

The abstract pattern of arguments provides a guide for the premise reconstruction. However, how can they be applied to real cases? What can the combination of the semantic and the logical dimensions of schemes tell us about students' possible prior beliefs? In order to illustrate how argumentation schemes can be used for analyzing students' arguments and revealing their unstated conceptions about science, we will apply the aforementioned causal and analogical schemes to real cases taken from classroom activities on predictive claims about floating and sinking.

\section{Applying Argumentation Schemes to Students' Arguments}

Argumentation schemes can be a resource for discovering the implicit beliefs affecting a student's learning process. In order to illustrate how this instrument can be an instrument of interpretation and a tool for investigating and bringing to light background beliefs, it is useful to show how it can be applied to real cases, pointing out the different steps of reconstruction of the different components and concepts underlying students' reasoning. In particular, argumentation schemes can be used in three phases. First, the argument will be reconstructed using the argumentation schemes. Then the background concepts underlying the student's reasoning will be 
Table 1 Description of the task

\begin{tabular}{lll}
\hline TASK & DESCRIPTION & QUESTIONS ASKED \\
\hline $\begin{array}{ll}\text { Ice cube } \\
\text { melting. }\end{array}$ & $\begin{array}{c}\text { There is a jug of water in which some ice } \\
\text { cubes are floating. }\end{array}$ & $\begin{array}{l}\bullet \text { What will happen to the level of the water } \\
\text { when the ice melts? } \\
\end{array}$ \\
\end{tabular}

retrieved. Finally the critical questions that can be used in each case will be listed, showing how the process of reconstruction can be connected with the dialogical and dialectical activity.

The sample arguments have been taken from an activity proposed to two classes of 44 students of compulsory education (12-13 years old and 14-15 years old) belonging to a public school in the metropolitan area of Barcelona. The students were requested to answer in writing two questions concerning Floating and sinking relative to the task summarized in Table 1.

The task followed the predict-observe-explain (POE) strategy (Champagne et al. 1980) used to test students' hypotheses about scientific relationships between events. First the students had to predict and justify the outcome of some event. Then they had to describe what they see happen. Finally, they had to reconcile any conflict between prediction and observation. The most representative of these arguments will be used in the following subsections to illustrate two argumentation schemes, argument from analogy and causality argument.

\subsection{Causality Argument 1}

The first scheme that will be applied is the one that was most commonly used in this activity, the causality argument. The semantic relationship between premises and conclusion is cause-effect, conceiving such category in a broader sense to include causal laws or intuitions about physical consequences:

Student: "I think the water will rise when the ice melts. As the ice melts it adds to the volume of the water, therefore increasing the water level."

The purpose of the activity was to elicit students' hypotheses about physical events. In this case the student advances a strong prediction ("the water will rise") from a relation between melting and increase of water level. The semantic relationship of such a correlation can be hypothetically reconstructed as a causal link (melting causes additional water).

Applying the argumentation scheme

\begin{tabular}{ll}
\hline FACTUAL PREMISE 1: & $\begin{array}{l}\text { In this case, melting of ice occurs in a jug of water. } \\
\text { IMPLICIT PREMISE 1: }\end{array}$ \\
Melting of ice results in water that is added to the volume of the existing water. \\
IMPLICIT PREMISE 2:
\end{tabular}


From this structure it is possible to advance a possible reconstruction of the student's background beliefs. The implicit premise 1 presupposes two additional implicit premises:

1. Melting of the ice causes the transformation of ice in water.

2. The melting of the ice floating in the water results in additional water.

Such relations result in a third implicit premise:

IMPLICIT PREMISE 3: The ice is "added" to the water (or rather, the ice is not taking any volume in the water).

Obviously, this is simply a reconstruction, which even if reasonable or the most reasonable one does not reveal what the students actually believe, but only what they are taking for granted in their arguments. Such implicit premises can be used as a starting point for investigating what the students actually hold. ${ }^{1}$ For instance, we can notice how the analysis of the concept of "to add" can reveal further possible implicit premises, which can stem from possible misconceptions about the nature of ice. For example, the fact that there is a change of state of the ice from solid to liquid can be interpreted as a difference in mass and not as a difference in volume. The student bringing forward this argument may have not considered that the ice is floating because it is less dense, that is, its mass is the same but its volume is bigger. Such hypotheses on students' beliefs can be assessed through critical questions or counterarguments during the discussion phases.

Possible Critical questions

$\mathrm{CQ}_{1}$ : Does the melting of the ice results in additional water? So what will happen when ice turns back to water liquid? Does will occupy more or less space?

$\mathrm{CQ}_{2}$ : Why floating ice is partly outside the water? Does change of state cause more mass? Does the mass change?

$\mathrm{CQ}_{3}$ : If the mass stays the same, how is it possible for the water level to rise?

\subsection{Causality Argument 2}

In the previous case (causality argument 1 ) the causal relation was left implicit and could be based on observation. In the following case, the student proceeds from a law of physics that he makes explicit and uses for drawing the conclusion:

Student 1: "I think that when the ice melts the water level will rise because the ice is not but solid water. And solid is more compact than the liquid and when,

\footnotetext{
1 This activity was carried out in the classroom with the students. The discussion among the students was guided by the researchers by using critical questions, underscoring the defeasible points of the students' predictive claims. All the discussions were recorded.
} 
when it becomes liquid and atoms are spread more apart and they become free and then... they take up more space and the water level will rise".

The nature of the reasoning is the same as the causal argument 1 (from a cause to an effect) even if the epistemic nature of the generalization is different. The structure of this argument can be reconstructed by applying the argument from cause to effect, showing the factual and causal premises that can be retrieved from the text.

Applying the argumentation scheme

\begin{tabular}{ll}
\hline FACTUAL PREMISE 1: & In this case, melting occurs. \\
CAUSAL LINK 1: & $\begin{array}{l}\text { If melting occurs, then atoms are spread further apart because a solid is more } \\
\text { compact than a liquid. }\end{array}$ \\
CONCLUSION 1: & In this case, atoms are spread further apart. \\
CAUSAL LINK 2: & If atoms are spread further apart, then they will take up more space. \\
CONCLUSION 2: & Therefore in this case, atoms will take up more space. \\
IMPLICIT PREMISE: & If the atoms of water take up more space, the water level will rise. \\
CONCLUSION 2: & Therefore water level in the jug will rise.
\end{tabular}

This reconstruction can reveal, generically, the implicit premises taken for granted by the students. However, if we critically analyze the reconstructed premises according to the argument structure, we can reveal possible background beliefs underlying the student's reasoning. For instance, causal link 1 presupposes the following possible implicit assumption:

1. If solid materials melt, their atoms will always be more spread apart (Melting always cause a wider distance between atoms).

Moreover, the second causal link presupposes the following premise:

2. The wider distance between the atoms causes an increase in the volume of the material.

The background beliefs of the student can be tentatively retrieved from the reconstructed premises. He is actually holding that all solid materials are more compact than liquids, using a universal generalization and a concept whose meaning can be controversial (does it mean denser?). The critical questions can be used to investigate the student's beliefs, leading him to specify the concepts he is using and reason on the universal law advanced. On this view, the reconstruction of the argument, carried out starting from the implications of the student's explicit premises, shows crucial concepts that can be discussed and delved into. The following critical questions can provide guidance to the further dialogue:

Possible Critical questions

$\mathrm{CQ}_{1}$ : Is it true that when solids become liquids their atoms are more apart to each other? Does the same happen with ice and liquid water?

$\mathrm{CQ}_{2}$ : What facts that you have observed can support this generalization? 


\subsection{Analogical Argument}

In analogical arguments the relationship between the compared concepts or correlations is implicit and needs to be reconstructed. Analogical arguments can be used when the causal principle is unknown, to draw a conclusion based on experience instead of previous knowledge (Juthe 2005: 4). For example we consider the following argument:

Student: "I think that when the ice melts, the water level will rise a little, I am watching the news and, they always say that the sea level is rising and the reason why this is happening is the climate change, because it is warmer, ice melts in the Antarctic, so therefore I have related this to the glass and I think so on".

Applying the argumentation scheme

\begin{tabular}{ll}
\hline GENERALIZATION: & Ice melting at the poles (climate change) is similar to ice melting in the jug. \\
SIMILARITY: & The ice melting at the poles results in a rise of the sea level. \\
CONCLUSION: & Therefore, the ice melting in the jug will result in a rise of the water level.
\end{tabular}

The implicit premise in this case is the generic quality (Macagno and Walton 2009) under which the terms of the comparison fall. In this case the similarity is possible because the ice in the jug and the ice at the poles are regarded as specific instances of "melting ice" or more simply "ice" without any qualification. The difference between the two instances that is relevant and essential for the consequence "rise of water level" is the location, which the student does not take into consideration. It is because not the whole icecap of Antarctica is floating on water that the sea level raises when the ice melts.

According to the reconstruction of the analogical argument, the student holds that the melting of the ice is the only cause responsible for the increase of the water level, without considering the location of the ice or whether it is floating or not. This commitment can reveal possible background beliefs that need to be inquired into by asking critical questions. For example, the advanced analogical reasoning can be explained by supposing that the student does not know (or, depending on the level of education of the student, has not considered) the buoyancy force. In order to assess the reconstruction of the implicit beliefs the following critical questions can be asked:

\section{Possible Critical questions}

$\mathrm{CQ}_{1}$ : Are the two situations (melting ice because of the climate change and melting ice in jug) comparable from the perspective of the effects of the melting? $\mathrm{CQ}_{2}$ : Are there differences between the two situations, the origin of the ice or its location for example?

$\mathrm{CQ}_{3}$ : Is all ice on the earth floating?

$\mathrm{CQ}_{4}$ : Has the melting of floating ice the same effects as the ice that is on the earth?

These critical questions can guide the process of discussion concerning this type of reasoning. The students' replies can reveal other implicit premises and background beliefs, which can be used for further discussions. 


\section{Conclusion}

Studies on an argumentative approach to science education have grown in the last years. In particular, the importance of understanding and improving students' reasoning has been greatly stressed as an instrument for enhancing both teaching effectiveness and learning abilities. However, recent approaches have focused on the structure and in particular on the completeness of arguments, without investigating their nature, their logical properties and their content. Moreover, the reconstruction of the inferential (material) link has not been studied so far. In this paper we show and illustrate from a theoretical point of view how argumentation schemes can be used as instruments for reconstructing the premises left implicit in students' arguments.

Argumentation schemes can be considered as tools for specifying the possible quasi-logical relations between premises. They provide abstract structures representing the possible premises and conclusions that can be advanced. They can be considered as guides to the process of reasoning analysis and reconstruction, outlining the role of the explicit premises and the pattern of the hidden ones. Prior beliefs underlying an argument are not revealed by simply providing the missing premises constituting the logical minimum (van Eemeren et al. 1994: 90). Argumentation schemes are instruments for achieving the pragmatic optimum of discovering the semantic relation and the information presupposed by it. However, they can provide only tentative explanations that need to be tested through discussions led by the critical questions. On this view, the teacher's interpretation becomes the starting point of a dialogical activity aimed at reconstructing the tacit dimensions of arguments. This process of argument and premise reconstruction, leading to an investigation of implicit beliefs and activities aimed at a conceptual change, is represented in Fig. 4.

On the theoretical perspective advanced in this paper, argumentation schemes are regarded as instruments and guides for detecting, retrieving and assessing students' prior beliefs. They are presented as argumentative instruments both in the sense of

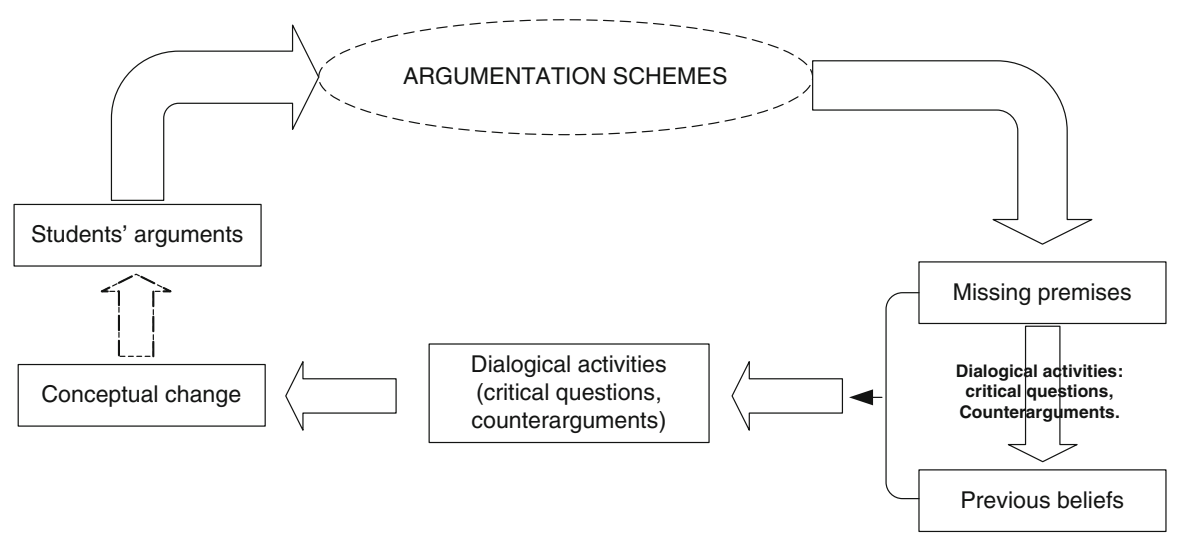

Fig. 4 The role of argumentation schemes in education 
instruments for analyzing arguments and producing arguments or counterarguments. They can be useful analytical tools, but such an analysis, given the presumptive nature of the schemes, needs to be confirmed and developed through a dialogical activity. These two dimensions can make argumentation schemes a potential resource for teaching.

Acknowledgments Fabrizio Macagno would like to thank the Fundação para a Ciência e a Tecnologia for the research grant on Argumentation, Communication and Context (PTDC/FIL-FIL/110117/2009) that made this collaboration possible.

\section{References}

Baker, M.J. 2003. Computer-mediated argumentative interactions for the co-elaboration of scientific notions. In Arguing to learn: Confronting cognitions in computer-supported collaborative learning environments, ed. J. Andriessen, M. Baker, and D. Suthers, 47-78. Dordrecht: Kluwer.

Bell, P., and M.C. Linn. 2000. Scientific arguments as learning artefacts: Designing for learning from the web with KIE. International Journal of Science Education 22(8): 797-817.

Braet, A. 1999. The enthymeme in Aristotle's rhetoric: From argumentation theory to logic. Informal Logic 19(2, 3): 101-117.

Bransford, J., A. Brown, and R. Cocking (eds.). 2000. How people learn: Brain, mind, experience and school. Washington, DC: National Research Council.

Carey, S. 2000. Science education as conceptual change. Journal of Applied Developmental Psychology 21(1): 13-19.

Castells, M., J. Enciso, J.M. Cerveró, P. López, and M. Cabellos. 2007. What can we learn from a study of argumentation in the students' answers and group discussion to open physics' problems? In Contributions from science education research, ed. A.R. Pintó and D. Couso, 417-431. Dordrecht: Springer.

Champagne, A.B., L.E. Klopfer, and J.H. Anderson. 1980. Factors influencing the learning of classical mechanics. American Journal of Physics 48: 1074-1079.

Chi, M.T.H., and R.D. Roscoe. 2002. The process and challenges of conceptual change. In Reconsidering conceptual change: Issues in theory and practice, ed. M. Limon and L. Mason, 3-27. Dordrecht: Kluwer.

Driver, R., P. Newton, and J. Osborne. 2000. Establishing the norms of scientific argumentation in classrooms. Science Education 84: 287-312.

Duit, R. 1999. Conceptual change approaches in science education. In New perspectives on conceptual change, ed. W. Schnotz, S. Vosniadou, and M. Carretero, 263-282. Oxford: Pergamon.

Duschl, R. 2007. Quality argumentation and epistemic criteria. In Argumentation in science education: Perspectives from classroom-based research, ed. S. Erduran and M. Jiménez-Aleixandre, 159-175. Amsterdam: Springer.

Duschl, R.A., K. Ellenboger and S. Erduran. 1999. Promoting argumentation in middle school science classrooms: A project SEPIA evaluation. Paper presented at the Annual meeting of the national association for research in science teaching (March 28-31), Boston, MA.

Erduran, S., and M.P. Jimenez-Aleixandre (eds.). 2007. Argumentation in science education: Perspectives from classroom-based research. Dordrecht: Springer.

Erduran, S., S. Simon, and J. Osborne. 2004. TAPping into argumentation: Developments in the application of Toulmin's Argument Pattern for studying science discourse. Science Education 88(6): 915-933.

Erduran, S., J. Osborne, and S. Simon. 2005. The role of argument in developing scientific literacy. In Research and the quality of science education, ed. K. Boersma, O. de Jong, H. Eijkelhof, and M. Goedhart, 381-394. Dordrecht: Kluwer Academic Publishers.

Finocchiaro, M. 2007. Arguments, meta-arguments, and metadialogues: A reconstruction of Krabbe, Govier, and Woods. Argumentation 21(3): 253-268.

Godden, D. 2010. The importance of belief in argumentation: Belief, commitment and the effective resolution of a difference of opinion. Synthese 172(3): 397-414.

Groarke, L., and C. Tindale. 2004. Good reasoning matters. Oxford: Oxford University Press. 
Guzzetti, B., T. Synder, G. Glass, and W. Gamas. 1993. Promoting conceptual change in science: A comparative meta-analysis of instructional interventions from reading education and science education. Reading Research Quarterly 28: 117-155.

Hahn, U., and M. Oaksford. 2006. A normative theory of argument strength. Informal Logic 26(1): 1-24.

Hastings, A.C. 1963. A reformulation of the modes of reasoning in argumentation. Evanston, IL: Ph.D. Dissertation, Northwestern University.

Hewson, P. 1992. Conceptual change in science teaching and teacher education. Paper presented at a meeting on "Research and Curriculum Development in Science Teaching," National Center for Educational Research, Documentation, and Assessment, Ministry for Education and Science, Madrid, Spain.

Hitchcock, D. 2003. Toulmin's warrants. In Anyone who has a view: Theoretical contributions to the study of argument, ed. F.H. van Eemeren, J.A. Blair, C.A. Willard, and A.F. Snoeck Henkemans, 69-82. Dordrecht, Boston, London: Kluwer Academic Publishers.

Jimenez-Aleizandre, M.P., A.B. Rodriguez, and R.A. Duschl. 2000. "Doing the lesson' or “Doing science': Argument in high school genetics. Science Education 84(6): 757-792.

Juthe, A. 2005. Argument by analogy. Argumentation 19:1-27.

Kelly, G.J., and C. Chen. 1999. The sound of music: Constructing science as sociocultural practices through oral and written discourse. Journal of Research in Science Teaching 36(8): 883-915.

Kelly, G., and A. Takao. 2002. Epistemic levels in argument: An analysis of university oceanography students' use of evidence in writing. Science Education 86: 314-342.

Koballa, T. 1992. Persuasion and attitude change in science education. Journal of Research in Science Teaching 29(1): 63-80.

Konstantinidou, A., J.M. Cerveró, and M. Castells. 2010. Argumentation and scientific reasoning: The "double hierarchy" argument. In Contemporary science education research: Scientific literacy and social aspects of science, ed. M.F. Taşar, and G. Çakmakc1, 61-70. Ankara, Turkey: Pegem Akademi.

Krabbe, E.C.W. 2003. Metadialogues. In Proceedings of the fifth conference of the international society for the study of argumentation, ed. F.H. van Eemeren, J.A. Blair, C.A. Willard, and A.F. Snoeck Henkemans, 641-644. Amsterdam: Sic Sat.

Krabbe, E.C.W. 2007. On how to get beyond the opening stage. Argumentation 21(3): 233-242.

Levi, D. 1995. The case of the missing premise. Informal Logic 17: 67-88.

Macagno, F., and D. Walton. 2009. Argument from analogy in law, the classical tradition, and recent theories. Philosophy and Rhetoric 42(2): 154-182.

Macagno, F., and D. Walton. 2010. Defeasible classifications and inferences from definitions. Informal Logic 30: 34-61.

Martins, I., E. Mortimer, J. Osborne, C. Tsatsarelis, and M.P. Jiménez Aleixandre. 2001. Rhetoric and science education. In Research in science education-past, present, and future, ed. H. Behrendt, $\mathrm{H}$. Dahncke, R. Duit, W. Gräber, M. Komorek, A. Kross, and P. Reiska, 189-198. Amsterdam: Kluwer.

Mestre, J.P. 1994. Cognitive aspects of learning and teaching science. In Teacher enhancement for elementary and secondary science and mathematics: Status, issues, and problems, ed. S.J. Fitzsimmons, and L.C. Kerpelman, 31-53. Arlington: National Science Foundation.

Nussbaum, M. 2011. Argumentation, dialogue theory, and probability modeling: Alternative frameworks for argumentation research in education. Educational Psychologist 46(2): 84-106.

Osborne, J. 2005. The role of argument in science education. Research and the Quality of Science Education 7: 367-380.

Osborne, J., S. Erduran, and S. Simon. 2004. Enhancing the quality of argumentation in school science. Journal of Research in Science Teaching 41(10): 994-1020.

Pera, M., and W. Shea. 1991. Persuading science. Canton, MA: Science History Publications.

Posner, G., K. Strike, P. Hewson, and W. Gertzog. 1982. Accommodation of s scientific conception: Towards a theory of conceptual change. Science Education 66(2): 211-227.

Rigotti, E. 1995. Verità e Persuasione. Il Nuovo Areopago 14(1): 3-14.

Roschelle, J. 1995. Learning in interactive environments: Prior knowledge and new experience. In Public institutions for personal learning: Establishing a research agenda, ed. J.H. Falk and L.D. Dierking, 37-51. Washington, DC: American Association of Museums.

Sampson, V., and D. Clark. 2008. Assessment of the ways students generate arguments in science education: Current perspectives and recommendations for future directions. Science Education 92(3): 447-472. 
Sandoval, W., and K. Millwood. 2005. The quality of students' use of evidence in written scientific explanations. Cognition and Instruction 23(1): 23-55.

Schwarz, B., and R. De Groot. 2007. Argumentation in a changing world. Computer-Supported Collaborative Learning 2: 297-313.

Simon, S. 2008. Using toulmin's argument pattern in the evaluation of argumentation in school science. International Journal of Research and Method in Education 31(3): 277-289.

Simons, H., J. Morreale, and B. Gronbeck. 2001. Persuasion in society. Thousand Oaks: Sage.

Songer, N., and Linn, M.C. 1991. How do students' views of science influence knowledge integration? Journal of Research in Science Teaching 28(9): 761-787.

Southerland, S., G. Sinatra, and M. Matthews. 2001. Belief, knowledge, and science education. Educational Psychology Review 13(4): 325-351.

Sutton, C. 1996. The scientific model as a form of speech. In Research in science education in Europe, ed. G. Welford, J. Osborne, and P. Scott, 143-152. London: Falmer Press.

Toulmin, S. 1958. The uses of argument. Cambridge: Cambridge University Press.

Toulmin, S., R. Rieke, and A. Janik. 1984. An introduction to reasoning, 2nd ed. New York: Macmillan. van Eemeren, F.H., and R. Grootendorst. 1984. Speech acts in argumentative discussions: A theoretical model for the analysis of discussions directed towards solving conflicts of opinion. Dordrecht: Floris Publications.

van Eemeren, F.H., and R. Grootendorst. 1992. Argumentation, communication, and fallacies: A pragmadialectical perspective. Hillsdale, NJ: Lawrence Erlbaum Associates.

van Eemeren, F.H., and R. Grootendorst. 2004. A systematic theory of argumentation. The pragmadialectical approach. Cambridge: Cambridge University Press.

van Eemeren, F.H., R. Grootendorst and F. Snoek-Henkemans. 2002. Argumentation. Analysis, evaluation, presentation. Mahwah, N.J.: Erlbaum.

van Eemeren, F.H., K. van de Glopper, R. Grootendorst, and R. Oostdam. 1994. Student performance in identifying unexpressed premisses and argumentation schemes. Argumentation and Advocacy 31: $151-162$.

van Rees, M.A. 2001. Argument interpretation and reconstruction. In Crucial concepts in argumentation theory, ed. F.H. van Eemeren, 165-199. Amsterdam: SicSat.

Walton, D. 1984. Logical dialogue-games and fallacies. Lanham, MD: University Press of America, Inc.

Walton, D. 1995. A pragmatic theory of fallacy. Tuscaloosa and London: The University of Alabama Press.

Walton, D. 2007. Media argumentation. Cambridge: Cambridge University Press.

Walton, D. and F. Macagno. 2006. Argumentative reasoning patterns. In Proceedings of ECAI conference 2006. Riva del Garda, 28 August-2 September 2006 (pp. 1-5). Amsterdam: IOS Press.

Walton, D., and E. Krabbe. 1995. Commitment in dialogue: Basic concepts of interpersonal reasoning. Albany: State University of New York Press.

Walton, D., C. Reed, and F. Macagno. 2008. Argumentation schemes. New York: Cambridge University Press. 